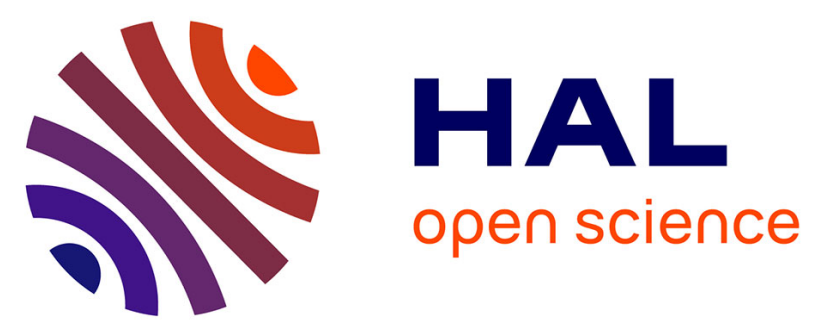

\title{
Tuning critical solution temperature for CO2 capture by aqueous solution of amine
}

Olympe Longeras, Arnaud Gautier, Karine Ballerat-Busserolles, Jean-Michel Andanson

\section{- To cite this version:}

Olympe Longeras, Arnaud Gautier, Karine Ballerat-Busserolles, Jean-Michel Andanson. Tuning critical solution temperature for CO2 capture by aqueous solution of amine. Journal of Molecular Liquids, 2021, 343, pp.117628. 10.1016/j.molliq.2021.117628 . hal-03419072

\section{HAL Id: hal-03419072 \\ https://hal.science/hal-03419072}

Submitted on 8 Nov 2021

HAL is a multi-disciplinary open access archive for the deposit and dissemination of scientific research documents, whether they are published or not. The documents may come from teaching and research institutions in France or abroad, or from public or private research centers.
L'archive ouverte pluridisciplinaire $\mathbf{H A L}$, est destinée au dépôt et à la diffusion de documents scientifiques de niveau recherche, publiés ou non, émanant des établissements d'enseignement et de recherche français ou étrangers, des laboratoires publics ou privés.

\section{(ㅇ)(1) $\$$}

Distributed under a Creative Commons Attribution - NonCommercial - NoDerivatives| 4.0 


\section{Tuning critical solution temperature for $\mathrm{CO}_{2}$ capture by aqueous solution of amine}

4

Olympe Longeras ${ }^{\mathrm{a}, \dagger}$, Arnaud Gautier ${ }^{\mathrm{a}}$, Karine Ballerat-Busserolles ${ }^{\mathrm{a}}$, Jean-Michel Andanson ${ }^{\mathrm{a},{ }^{*}}$

${ }^{a}$ Université Clermont Auvergne, CNRS, SIGMA Clermont, Institut de Chimie de ClermontFerrand, F-63000 Clermont-Ferrand, France.

${ }^{\dagger}$ Present address : Université de Rouen Normandie, UFR des Sciences et Techniques, Laboratoire SMS-EA3233, Place Emile Blondel, 76821, Mont-Saint-Aignan, France

* email : j-michel.andanson@uca.fr

\section{$\underline{\text { Abstract }}$}

Aqueous solution of amine is a mature technology to selectively absorb $\mathrm{CO}_{2}$ from an industrial exhaust. Monoethanolamine (MEA) is still considered as the reference amine and unfortunately, the energy necessary to desorb $\mathrm{CO}_{2}$ and recycle the solvent is limiting its use at industrial scale. The main cost of the process is the energy needed to heat the solvent over $100{ }^{\circ} \mathrm{C}$ to desorb the $\mathrm{CO}_{2}$. Several options to decrease this expense have been considered including the use of phase separation to reduce the volumes to be treated. It was then proposed to use aqueous solution of an amine exhibiting a lower critical solution temperature (LCST) at an adequate temperature. However, it is challenging to found a solvent able to absorb large quantity of $\mathrm{CO}_{2}$ and having an LCST at a suitable temperature. Deep eutectic solvent (DES) composed of oleic acid (hydrophobic) and lidocaine (amphiphilic) can be separated from water with either temperature or $\mathrm{CO}_{2}$ as stimuli. This DES has been used to adjust the critical solution temperature after sorption of $\mathrm{CO}_{2}$ in an aqueous solution of demixing amine. By only changing the ratio of the two components of the DES, the critical solution temperature can be tuned from around 30 to $70^{\circ} \mathrm{C}$. The addition of this DES into an aqueous solution of demixing amine could then substantially help to adapt the critical solution temperature of a solvent to the require conditions of $\mathrm{CO}_{2}$ capture process.

\section{$\underline{\text { Keywords }}$}

Deep eutectic solvent, $\mathrm{CO}_{2}$ capture, lower critical solution temperature 


\section{Introduction}

2

Currently the industrial technologies for $\mathrm{CO}_{2}$ capture processes are based on a $\mathrm{CO}_{2}$ separation from post-combustion effluent by gas dissolution in chemical absorbent solutions. The technology is mature enough to be integrated into industrial sites without strong modification of the plant.[1] The principle is based on $\mathrm{CO}_{2}$ absorption-desorption cycles. Carbon dioxide contained in gaseous effluents is selectively absorbed by solvents. Aqueous solutions of alkanolamine are selective absorbents[2] used in the decarbonation of natural gases. The affinity between the absorbent and the $\mathrm{CO}_{2}$ has to be precisely adjusted: if the interaction is too weak, the $\mathrm{CO}_{2}$ is not enough absorbed, however, if the interaction is too strong, the amount of energy to desorb will be extensive, the cycling process will be costly and not applicable at industrial scale. Aqueous solution of monoethanolamine (MEA) is the benchmark for post-combustion capture (PCC).[3] This amine has a strong affinity with $\mathrm{CO}_{2}$ leading to favorable kinetic of absorption. In the cycling process with this type of system, the $\mathrm{CO}_{2}$ desorption from an alkanolamine solution is highly energy consuming and not compatible with $\mathrm{CO}_{2}$ remediation applications. It is thus necessary to imagine new breakthrough processes allowing substantial energetic cost reduction. Tertiary alkanolamines such as methyldiethanolamines (MDEA) have therefore been proposed,[4] as the affinity between such amine and $\mathrm{CO}_{2}$ is reduced, decreasing the energetic cost of the regeneration. However, in that case, the kinetic of absorption is unfavorable, and if the solvent is really efficient to treat gases containing high concentrations of $\mathrm{CO}_{2}$, it necessitates very large installations and solvent quantities to treat the fume from post-combustion processes. Another option is to use an aqueous switchable solvent[5] possessing an LCST (lower critical solution temperature): while increasing the temperature, the solvent present a liquid - liquid phase separation at its critical temperature. The topic of phase change solvents for PCC have been recently reviewed.[3] In 2011 IFPEN proposed the DMX ${ }^{\circledR}$ process based on the use of high capacity and chemically stable demixing amines to replace classical alkanol amines for $\mathrm{CO}_{2}$ capture in industrial effluents.[6, 7] Thermomorphic biphasic solvent (TBS) have been widely studied by Zhang et al.[8-14] and Tan[15]. The solvent is an aqueous mixture of lipophilic amines exhibiting a liquid - liquid phase transition upon heating leading to a high carbon dioxide desorption at temperatures well below the boiling point of aqueous solutions. This technology uses heterogeneous absorbent solutions which becomes homogeneous upon carbon dioxide 
1 absorption and returns to two phases through heating. The organic phase acts as an extractive 2 agent, removing the amines from the aqueous phase and thus favorably displacing the 3 regeneration equilibrium. Zhang et al. have intensively worked on replacing steam stripping used

4 for carbon dioxide release with nucleation or agitation techniques.[9, 11] They pointed out that 5 the benefit of adding a hydrophobic organic solvent to reduce the operating temperature for 6 carbon dioxide desorption. Mixed phase-changed solvents have been investigated by Svendsen and coworkers[16-20] as a part of the European Union project iCap. The process is very similar

8 to $\mathrm{DMX}{ }^{\circledR}$ developed by IFPEN. Screening investigations to evaluate the $\mathrm{CO}_{2}$ absorption and desorption facilities of phase-change solvents have been completed.[21, 22]

Since the initial work from Abbott and collaborators, deep eutectic solvents (DES) have gained a large interest from the scientific community.[23, 24] DES are mixtures with melting temperatures far below the melting temperature of the initial components.[25] The existence of DES is generally explained by favorable specific interactions between the different chemicals of the mixture. Many DES are obtained by the mixing of a donor and an acceptor of hydrogen bond. DES with specific properties can be designed to target particular physico-chemical properties: as example, hydrophobic DES has been developed for extraction of a broad range of molecules[26] and ions[27] from water. A first DES - water system with an LCST at $25^{\circ} \mathrm{C}$ has been recently observed.[28] This DES is composed of oleic acid (OA) and lidocaine (LD) which was first introduced by Bica et al.[29] The existence of the LCST has been explained by the variation of pKa of the amine: the temperature increase is inducing a fast decrease of the solubility of the amphiphilic lidocaine in water up to the phase separation. Although the system is fully miscible below $25^{\circ} \mathrm{C}$, at $50^{\circ} \mathrm{C}$ only $5 \mathrm{wt} \%$ of water is present in the organic phase and less than $0.5 \mathrm{wt} \%$ of

23 DES is detected in the aqueous phase.[28] (OA). First, we found that the addition of carbon dioxide into an aqueous solution of DES (OA:LD) is triggering a switch from monophasic to biphasic. However, the quantity of $\mathrm{CO}_{2}$ absorbed in the aqueous solution of DES (OA:LD) is irrelevant for the topic of $\mathrm{CO}_{2}$ capture. We then decided to add another amine to increase the amount of absorbed $\mathrm{CO}_{2}$. Several amines including monoethanol amine (MEA), piperidine, 2-methylpiperidine, 4-methylpiperidine, Nmethylpiperidine, N-ethylpiperidine were evaluated. The existence of an LCST between 25 and 
$80^{\circ} \mathrm{C}$ after addition of $\mathrm{CO}_{2}$ for several compositions were tested for each amine. LCST was only

2 observed for mixtures with $\mathrm{N}$-methylpiperidine (NMPi) and N-ethylpiperidine. NMPi was

3 selected as the most promising amine for $\mathrm{CO}_{2}$ capture application. This tertiary amine with a $\mathrm{pKa}$

4 around 10, [30] is also increasing the $\mathrm{CO}_{2}$ absorption compared to the LD with a pKa of around

5 8. [31] Therefore, NMPi was selected to evaluate the ability of \{DES (OA:LD) + water + Amine $\}$

6 mixtures to be efficient for $\mathrm{CO}_{2}$ capture. Most studies using aqueous amine solutions for $\mathrm{CO}_{2}$

7 capture are using concentrations of around $30 \mathrm{wt} \%$ of organic molecules.[20, 32] Therefore in the

8 present study, the experiments are realized with solvents composed of DES (OA:LD), NMPi and

9 water and with fixe amount of water at $70 \mathrm{wt} \%$. In particular, we studied the impact of DES and NMPi concentrations on the critical solution temperature. After this optimization step, we finally evaluated the quality of the separation of this new solution for carbon capture.

\section{$12 \quad$ Results and discussion}

\section{Inducing a reversible phase separation by addition of $\mathrm{CO}_{2}$ in aqueous solution of DES (OA:LD)}

While mixed with water at $20^{\circ} \mathrm{C}$, only the DES (OA:LD) with initial concentrations of $\mathrm{x}_{\mathrm{OA}}$ between 0.45 and 0.60 are homogeneous. For lower concentrations of OA, the DES is partially solid, and for higher concentration of $\mathrm{OA}$, the aqueous mixtures are biphasic liquid - liquid at $20^{\circ} \mathrm{C}$.[28] The addition of $\mathrm{CO}_{2}$ into the aqueous DES were then realized for OA:LD molar ratios of $45: 55,50: 50,55: 45$ and $60: 40$. At $20^{\circ} \mathrm{C}$, when $\mathrm{CO}_{2}$ is bubbled at atmospheric pressure in an aqueous DES with $70 \mathrm{wt} \%$ of water, the mixture became white within few minutes under stirring. The possibility to induce the phase separation by an increase of the temperature was avoided by keeping the samples at $20^{\circ} \mathrm{C}$ in water bath and under a vigorous stirring. After 1 hour when the flow of $\mathrm{CO}_{2}$ and the stirring are stopped, a decantation in 2 liquid phases is observed. Then, stirring is restarted and $\mathrm{N}_{2}$ is bubbled into the biphasic mixtures, and the systems are coming back to monophasic liquid in less than 1 hour. An example of these visual observations is given in Figure 1. All tested ratio of DES (OA:LD molar ratios of 45:55, 50:50, 55:45 and 60:40) give the same behavior : monophasic before addition of $\mathrm{CO}_{2}$, biphasic liquid - liquid after absorption of $\mathrm{CO}_{2}$ at $20^{\circ} \mathrm{C}$ and monophasic again after flushing $\mathrm{N}_{2}$. These observations are comparable to those made on an ionic liquid based on tetrabutylphosphonium $\mathrm{N}$-trifluoromethanesulfonyl leucine. 
$1 \mathrm{CO}_{2}$ bubbling at $20^{\circ} \mathrm{C}$ was inducing the phase separation while bubbling $\mathrm{N}_{2}$ was switching back 2 the system to monophasic.[33]

(1)

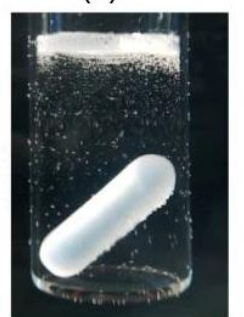

(2)

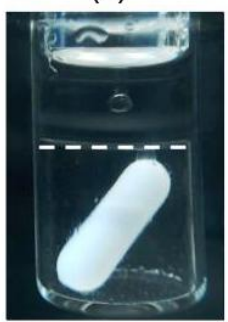

(3)

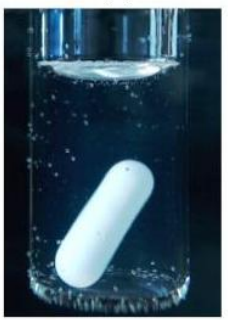

Figure 1: Pictures of DES (OA:LD) - water mixture, before addition of $\mathrm{CO}_{2}$ (1), after addition of $\mathrm{CO}_{2}$ (2), and after addition of $\mathrm{N}_{2}$ (3). The DES is composed of $60 \mathrm{~mol} \%$ of OA and $40 \mathrm{~mol} \%$ of LD and before the addition of $\mathrm{CO}_{2}$ the mixture is composed of $30 \mathrm{wt} \%$ of DES and $70 \mathrm{wt} \%$ of $\mathrm{H}_{2} \mathrm{O}$. The experiment was performed in a water bath thermostated at $20^{\circ} \mathrm{C}$. The vial is containing $2.5 \mathrm{ml}$ of solution, and the aqueous phase is the bottom phase. White dashes have been added to help discerning the liquid - liquid interface.

Switch hydrophobicity of this DES-water with temperature has already been investigated. [28] The system is composed of OA (an oil), water and LD. At low temperature, the amphiphilic lidocaine is making oil and water to remain together in a single phase. When the temperature is increased, the quantity of ions is decreased[28] and the solubility of neutral LD is much smaller than cationic LD.[31] Therefore, the affinity between water and organic compounds is disrupted by the increase of temperature and the liquid - liquid phase separation is induced with DES on one side and water on the other. The similar behavior is observed here with $\mathrm{CO}_{2}$ absorption in DES-water at ambient temperature. Indeed, $\mathrm{pH}$ of solution is acidified when $\mathrm{CO}_{2}$ is absorbed, thus solubility of LD in water is reduced initiating a phase separation.

For the considered concentrations of (OA:LD), the density of the DES is always between 0.94 and $0.96 \mathrm{~g} / \mathrm{cm}^{3}$.[29] In the example shown in Figure 1, the volume ratio between the organic and aqueous phase is close to the ratio of water and DES. Nevertheless, for mixture with higher amount of OA, the volume of the aqueous phase tends to decrease. This could illustrate the nonideal separation between the DES and water. In particular, since the water volume is smaller than expected, the quantity of water in the organic phase should be significant.

A small increase of temperature and the addition of $\mathrm{CO}_{2}$ are two stimuli that are inducing a phase separation between the DES (OA:LD) and water. In either case, the phase separation is 
1 reversible by decreasing the temperature or by removing the $\mathrm{CO}_{2}$. Depending on the application,

$2 \quad \mathrm{CO}_{2} / \mathrm{N}_{2}$ stimulus could be more appropriate than changing the temperature.

$3 \mathrm{pKa}$ of $\mathrm{LD}$ is 8.0 at $25^{\circ} \mathrm{C},[31]$ and because of its low pKa, this tertiary amine could not be 4 considered as a good amine for $\mathrm{CO}_{2}$ capture.[34] Indeed, the mixture with $30 \mathrm{wt} \%$ of DES (2:1)

5 can only absorbed around $0.3 \mathrm{wt} \%$ of $\mathrm{CO}_{2}$ which is far from a benchmark system like MEA 6 water which are absorbing more than $10 \mathrm{wt} \%$ ( $\mathrm{g}$ of $\mathrm{CO}_{2} / \mathrm{g}$ of solvent).[35] It was then decided to add another tertiary amine with a higher pKa to improve the absorption of $\mathrm{CO}_{2}$. DES (OA:LD) -

$8 \mathrm{NMPi}$ - water $-\mathrm{CO}_{2}$ was selected after a screening over potential amines.

\section{Impact of the composition of the solvent on the LCST in DES - NMPi - water - $\mathrm{CO}_{2}$ mixtures}

To evaluate $\mathrm{CO}_{2}$ absorption in different conditions, the loading charge $\alpha$ is often used: $\alpha$ is the molar ratio of carbon dioxide per amine. Since aqueous solution of LD has not shown high ability to absorb the $\mathrm{CO}_{2}$, $\mathrm{LD}$ has not been considered for the calculation of the loading charge of $\mathrm{CO}_{2}$ and only the concentration of NMPi has been taken into account:

$$
\alpha=\text { mole } \mathrm{CO}_{2} / \text { mole NMPi }
$$

This parameter is employed to describe $\mathrm{CO}_{2}$ absorption. However, $\alpha$ is only utilized when a reactive amine is added to the solvent. To facilitate the comparison with other processes, $\mathrm{CO}_{2}$ absorption can also be defined by the mass ratio (wt \%): $\mathrm{g}$ of $\mathrm{CO}_{2} / \mathrm{g}$ of solvent.

$\mathrm{CO}_{2}$ sorption experiments was first realized in a solution containing $70 \mathrm{wt} \%$ of water, $15 \mathrm{wt} \%$ of DES (OA:LD) and $15 \mathrm{wt} \%$ of NMPi. Flowing gaseous $\mathrm{CO}_{2}$ above the solution for $45 \mathrm{~min}$. induce a $\mathrm{CO}_{2}$ sorption up to $\alpha$ around 0.6 which correspond to $4 \mathrm{wt} \%$ ( $\mathrm{g}$ of $\mathrm{CO}_{2} / \mathrm{g}$ of solvent). When bubbling directly $\mathrm{CO}_{2}$ in the liquid phase, the sorption is faster and an $\alpha=0.4$ is reach in only 6 min. The addition of NMPi has been clearly improving the solubility of $\mathrm{CO}_{2}$; it has increased from $0.3 \mathrm{wt} \%$ with DES to $4 \mathrm{wt} \%$ when replacing half of the DES by NMPi. After the $\mathrm{CO}_{2}$ sorption, a vial containing $2 \mathrm{ml}$ of sample is transfer into a water bath to measure the critical solution temperature while increasing the temperature up to $80^{\circ} \mathrm{C}$. In the case of $\alpha=0.40$, a phase separation is observed at $43^{\circ} \mathrm{C}$ (Table 1 , entry 1) while without $\mathrm{CO}_{2}$ this mixture does not show a critical solution temperature up to $80^{\circ} \mathrm{C}$. 
The impact of the concentrations of each component was evaluated by modifying their

2 concentrations. First, the ratio of DES and NMPi were changed while keeping the quantity of

3 water constant at $70 \mathrm{wt} \%$ and the quantity of $\mathrm{CO}_{2}$ at $\alpha=0.4$. Compared to the 70-15-15 (Table 1,

4 entry 1), the critical solution temperature is lowered with other DES / NMPi ratios tested. With

$510 \mathrm{wt} \%$ of DES, the critical solution temperature is at $28^{\circ} \mathrm{C}$, while with $20 \mathrm{wt} \%$, it is $36^{\circ} \mathrm{C}$

6 (Table 1,entries 2 and 3). Without NMPi (30 wt\% DES 2:1 and $70 \mathrm{wt} \% \mathrm{H}_{2} \mathrm{O}$ ) the system is

7 already biphasic at room temperature. In absence of DES (30 wt $\%$ of NMPi in $70 \mathrm{wt} \%$ of water)

8 the system is also already biphasic in presence of $\mathrm{CO}_{2}(\alpha=0.4)$ at room temperature. While

9 keeping $70 \mathrm{wt} \%$ of water, $\alpha=0.40$ and OA/LD $=67 / 33$, (Table 1 , entries $1-5$ ), the highest critical

10 solution temperature observed is when using the same quantity of NMPi and DES; $15 \mathrm{wt} \%$ of

11 each component. Therefore, the solvent composed of DES-NMPi-water 15-15-70 (wt\%) is

12 selected as an optimal composition of the solvent for $\mathrm{CO}_{2}$ capture. Indeed, its LCST is

13 appropriate for the application: above the typical temperature of $\mathrm{CO}_{2}$ capture process $\left(40^{\circ} \mathrm{C}\right)$ and

14 not too high to reduce required energy.

15 Table 1: Critical solution temperature of mixtures after absorption of $\mathrm{CO}_{2}{ }^{1}{ }^{1}$ : LCST: low critical solution 16 temperature corresponding to the cloud point while heating. ${ }^{2}: \mathrm{L}-\mathrm{L}$ correspond to a system which is always

17 biphasic liquid - liquid between 25 and $80^{\circ} \mathrm{C}$. ${ }^{3}: \mathrm{L}$ is a mixture which is always monophasic in this range 18 of temperature.

\begin{tabular}{|c|c|c|c|c|c|c|}
\hline \multirow[t]{2}{*}{ Entry } & \multicolumn{3}{|c|}{ Solvent composition } & \multirow{2}{*}{$\begin{array}{c}\text { DES ratio } \\
\text { OA/LD } \\
(\mathrm{mol} \%)\end{array}$} & \multirow{2}{*}{$\begin{array}{c}\mathrm{CO}_{2} \text { loading } \\
\mathrm{mol} \mathrm{CO}_{2} / \\
\text { mol NMPi }\end{array}$} & \multirow{2}{*}{$\begin{array}{c}\mathrm{LCST}^{\mathrm{I}} \\
\left({ }^{\circ} \mathrm{C}\right)\end{array}$} \\
\hline & $\begin{array}{l}\text { NMPi } \\
(\mathrm{wt} \%)\end{array}$ & $\begin{array}{c}\text { DES } \\
(\mathrm{wt} \%)\end{array}$ & $\begin{array}{c}\mathrm{H}_{2} \mathrm{O} \\
(\mathrm{wt} \%)\end{array}$ & & & \\
\hline 1 & 15 & 15 & 70 & $67 / 33$ & 0.40 & 43 \\
\hline 2 & 30 & 0 & 70 & - & 0.40 & $\mathrm{~L}-\mathrm{L}^{2}$ \\
\hline 3 & 20 & 10 & 70 & $67 / 33$ & 0.40 & 28 \\
\hline 4 & 10 & 20 & 70 & $67 / 33$ & 0.40 & 36 \\
\hline 5 & 0 & 30 & 70 & $67 / 33$ & - & L-L ${ }^{2}$ \\
\hline 6 & 15 & 15 & 70 & $50 / 50$ & 0.40 & ${\mathrm{~L}-\mathrm{L}^{2}}^{2}$ \\
\hline 7 & 15 & 15 & 70 & $60 / 40$ & 0.40 & 31 \\
\hline 8 & 15 & 15 & 70 & $71 / 29$ & 0.40 & 51 \\
\hline 9 & 15 & 15 & 70 & $75 / 25$ & 0.40 & 55 \\
\hline 10 & 15 & 15 & 70 & $80 / 20$ & 0.40 & 69 \\
\hline 11 & 15 & 15 & 70 & $67 / 33$ & 0.00 & $\mathrm{~L}^{3}$ \\
\hline 12 & 15 & 15 & 70 & $67 / 33$ & 0.19 & 65 \\
\hline 13 & 15 & 15 & 70 & $67 / 33$ & 0.25 & 56 \\
\hline 14 & 15 & 15 & 70 & $67 / 33$ & 0.37 & 51 \\
\hline 15 & 15 & 15 & 70 & $67 / 33$ & 0.47 & 33 \\
\hline
\end{tabular}




\begin{tabular}{lllllll}
16 & 15 & 15 & 70 & $67 / 33$ & 0.48 & 28 \\
17 & 15 & 15 & 70 & $67 / 33$ & 0.53 & 27 \\
\hline
\end{tabular}

1

2 As the ratio of the two constituents of the DES can be modified, we decided to study the 3 impact of their molar concentrations on the critical solution temperature after absorption of $\mathrm{CO}_{2}$ $4 \quad(\alpha=0.40)$. While the phase separation was observed to be $43^{\circ} \mathrm{C}$ with the concentration of $567 \mathrm{~mol} \%$ of OA (DES 2:1), changing the molar ratio of the two constituents has an obvious 6 impact on the critical temperature. The temperature of the phase separation increases 7 continuously from around 30 to $70^{\circ} \mathrm{C}$ when increasing the amount of $\mathrm{OA}$ from 60 to $80 \mathrm{~mol} \%$ in 8 the DES (Figure 2). All concentrations and temperatures are given in Table 1, entries 1 and 7 to 9 10. With lower concentration of OA (DES 1:1) the mixture is already biphasic at room 10 temperature. It is worth to mention that for the range of concentrations considered in this work, 11 oleic acid is the main substance of the DES and it is a fatty acid obtained from vegetal oil. Oleic 12 acid is up to $80 \mathrm{wt} \%$ of the fatty acid composition of high oleic vegetable oils.[36] It is then 13 interesting to note that it is possible to tune the property of the solution to have the separation at a 14 specific temperature in order to adapt to the requirement of a chemical process. This adjustment 15 of the critical temperature can be achieved simply by changing the composition of the solvent 16 (ratio of DES/NMPi as well as ratio OA/LD) without changing any of the others parameters.

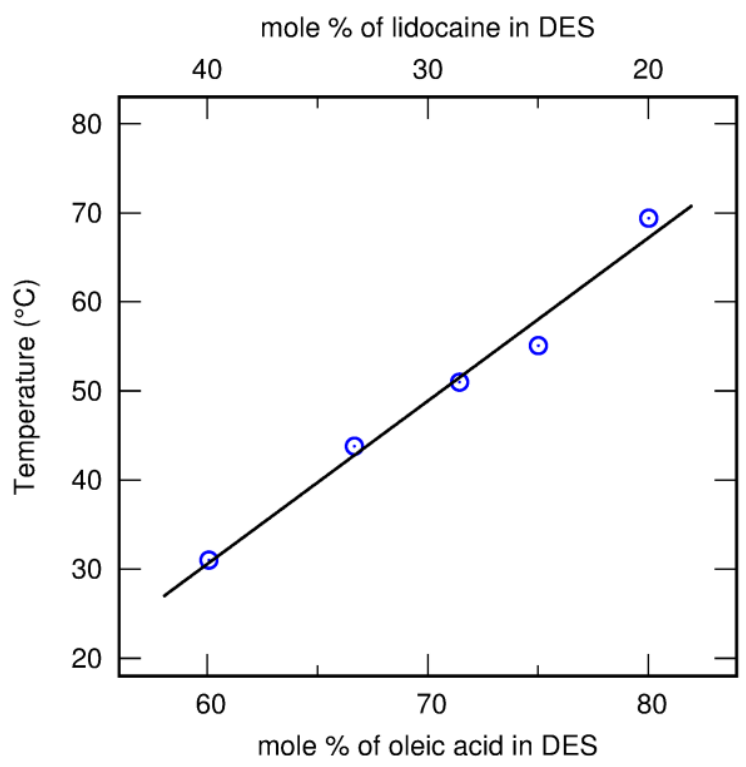


1 Figure 2: Evolution of critical solution temperature while changing the ratio of OA and LD in the DES.

2 Initial composition of all samples is $70 \mathrm{wt} \%$ of water, $15 \mathrm{wt} \%$ of DES and $15 \mathrm{wt} \%$ of NMPi and the

3 loading of $\mathrm{CO}_{2}$ is $\alpha=0.40$. Black line is only a guide for the eye.

4 We also studied the impact of the $\mathrm{CO}_{2}$ concentration on the critical temperature. This 5 investigation was realized with solvent composed of 70, 15 and $15 \mathrm{wt} \%$ of water, DES and $6 \mathrm{NMPi}$, respectively, and with a 2:1 (OA:LD) molar ratio in the DES. Changing the $\mathrm{CO}_{2}$ loading 7 is also impacting the critical solution temperature. When increasing the $\mathrm{CO}_{2}$ loading from 0.19 to 80.54 , the temperature constantly decreases from around 65 to $27^{\circ} \mathrm{C}$ (Figure 3). Without $\mathrm{CO}_{2}$, the 9 phase separation could not be observed up to $80^{\circ} \mathrm{C}$. The decrease of the critical solution 10 temperature with the addition of $\mathrm{CO}_{2}$ is coherent with the observation of other tertiary amine 11 water mixture, where the addition of $\mathrm{CO}_{2}$ is also inducing a phase separation at constant 12 temperature in similar condition.[37] This is also in accordance with the behavior of aqueous 13 solutions of alkyl-piperidines in presence of $\mathrm{CO}_{2}$ (with similar concentrations of amine and $\left.14 \mathrm{CO}_{2}\right) \cdot[38]$

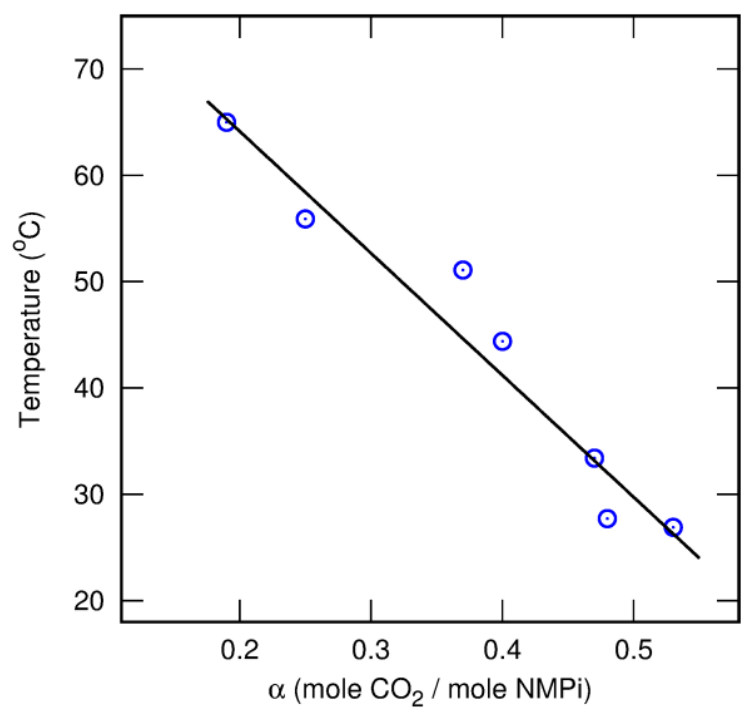

Figure 3: Impact of the amount of $\mathrm{CO}_{2}$ on the critical solution temperature. Initial composition of all samples is $70 \mathrm{wt} \%$ of water, $15 \mathrm{wt} \%$ of DES (2:1) and $15 \mathrm{wt} \%$ of NMPi. Black line is only a guide for the eye. 
1 For a carbon capture application the kinetic of separation of two phases is a critical factor.

2 While considering the DES (2:1) - NMPi - water system (15, 15 and $70 \mathrm{wt} \%$, respectively) with

3 a sorption of $\mathrm{CO}_{2}(\alpha=0.40)$ at $70^{\circ} \mathrm{C}$, the separation of the two phases is occurring within few

4 minutes. Above this temperature, separation of two phases is not improved (see supplementary

5 information, Figure S1) and would require more energy. Thus, $70^{\circ} \mathrm{C}$ has been selected as optimal

6 separation temperature. The kinetic of separation is naturally depending of several parameters

7 including residual movement of the fluids and shape of the container. In the illustration presented

8 in Figure 4, the apparition of the two phases occurs during the first minute, and the volume of the

9 two phases is constant after only three minutes. The bottom phase (aqueous) is clear during the

10 all experiment while it takes dozens of minutes for the top phase (organic) to become nearly

11 transparent. The cloudiness of the phase is most probably corresponding to remaining droplets of

12 water in the organic phases.

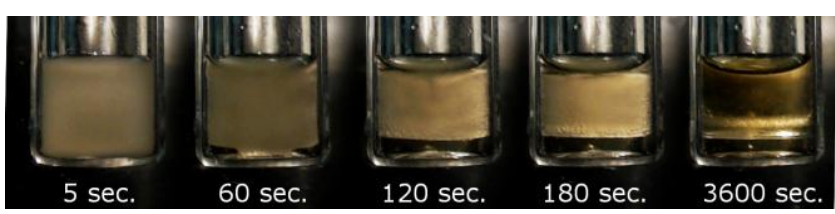

Figure 4: Pictures of the separation of the two phases without stirring at $70^{\circ} \mathrm{C}$ of a solvent with DES 2:1, NMPi and water $(15,15$, and $70 \mathrm{wt} \%)$ after sorption of $\mathrm{CO}_{2}(\alpha=0.40)$. After an equilibration of 15 minutes at $40^{\circ} \mathrm{C}$ (homogeneous transparent liquid), the vial containing $0.67 \mathrm{~g}$ of solution was place in a water bath at $70^{\circ} \mathrm{C}$.

DES and water have similar densities and the initial amount of water in the solution being $70 \mathrm{wt} \%$, we could then expect that, if water and DES are well separated, the aqueous phase

21 should be around $70 \%$ of the total volume. Nevertheless, as observed on Figure 4, the volume of 22 the aqueous phase is smaller than the organic phase. Then, an experiment was realized in a NMR 23 tube to assess the volume ratio of the two phases (see supplementary information Figure S1). In 24 coherence with the picture of Figure 4, the volume of the organic phase was estimated to be $70 \%$ $+/-3 \%$ of the total volume at $70^{\circ} \mathrm{C}$. Water should then be poorly separated and present in large quantity in both phases. 
The system was then evaluated by estimating the amount of chemical after 15 minutes at $70^{\circ} \mathrm{C}$

2 in both phases. Karl-Fischer titration was used to determine the quantity of water in aqueous and

3 organic phases. Water is present in both phases in large quantity: water is the main compound in

4 the two phases with 81 and $57 \mathrm{wt} \%$ in aqueous and organic phases, respectively. Quantifications

5 of OA, LD and NMPi were obtained by quantitative proton NMR (q ${ }^{1} \mathrm{H}$ NMR, spectra are given

6 in SI). In the aqueous phase, OA has not been detected and the quantity of LD is below $0.5 \mathrm{wt} \%$.

7 In the organic phase, the ratio of $\mathrm{OA}$ and $\mathrm{LD}$ is $2: 1$, identical to the initial ratio, as expected

8 because of the low concentrations of DES constituents in the aqueous phase. Unlike OA and LD,

9 NMPi is poorly separated with 16 and $11 \mathrm{wt} \%$ in organic and aqueous phase, respectively.

10 Finally, the amounts of $\mathrm{CO}_{2}$ present in both phases are obtained by IR spectroscopy. The $\mathrm{CO}_{2}$

11 signal at around $2340 \mathrm{~cm}^{-1}$ has not be observed indicating the absence of physi-sorption, even at

$1240^{\circ} \mathrm{C}$ before heating, meanings that all absorbed $\mathrm{CO}_{2}$ have reacted with the aqueous solution. One

13 band is clearly visible at $1357 \mathrm{~cm}^{-1}$ when comparing solution before and after sorption as shown

14 in Figure 5. This band is assigned to the carboxylate symmetric stretching vibration of $\mathrm{HCO}_{3}{ }^{-}$

15 . [39] Variation of the quantity of $\mathrm{HCO}_{3}{ }^{-}$in both phases is obtained using the intensity at this

16 wavenumber. The phase separation induces an increase by $20 \%$ in the aqueous phase (green

17 spectra in Figure 5), while the concentration decreases by $15 \%$ in the organic phase (black 18 spectra).

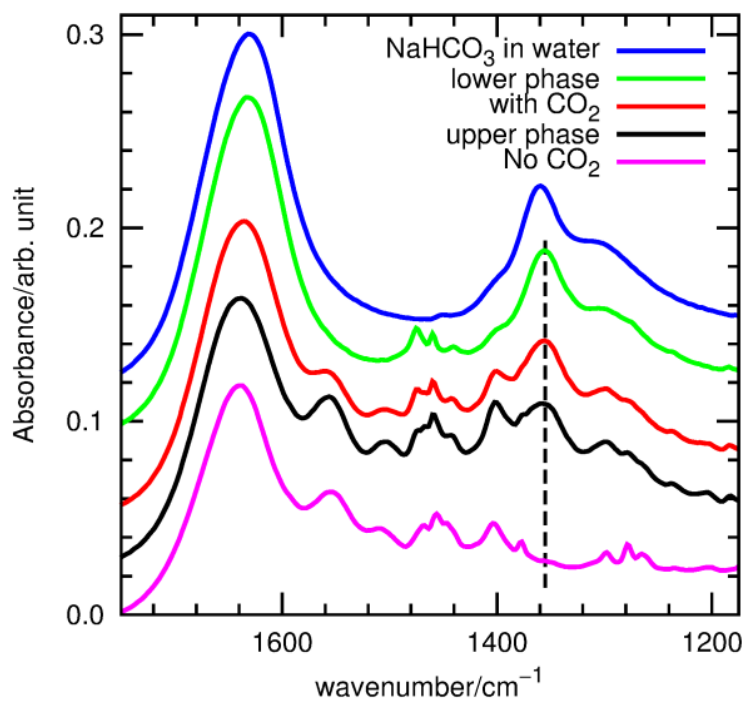

20 Figure 5: Infrared spectra of sample with DES 2:1, NMPi and water (15, 15, and 70 wt $\%)$ before $21 \mathrm{CO}_{2}$ sorption (purple spectra), after sorption of $\mathrm{CO}_{2}(\alpha=0.40)$ and before phase separation (red spectra), 
1 and after phase separation at $70^{\circ} \mathrm{C}$ : top - organic phase (black spectra) and bottom - aqueous phase (green

2 spectra). IR spectra of aqueous solution of $\mathrm{CO}_{2}\left(\mathrm{HCO}_{3}^{-}\right)$is also given as comparison (blue spectra). Dotted

3 line at $1357 \mathrm{~cm}^{-1}$ corresponds to the signal used to estimate the quantity of $\mathrm{CO}_{2}$. IR spectra have been

4 shifted for clarity reason.

5 Considering the concentration of $\mathrm{CO}_{2}$ estimated from IR spectroscopy, we can evaluate that 6 around $60 \%$ of the absorbed $\mathrm{CO}_{2}$ remains in the organic phase and only $36 \%$ of the $\mathrm{CO}_{2}$ is in the 7 aqueous phase. The residual $4 \%$ could be explained by a possible small desorption of $\mathrm{CO}_{2}$ during 8 the heat from 40 to $70^{\circ} \mathrm{C}$ and also by the uncertainty of this rough methodology. For each 9 compound, the estimation of the distribution between the two liquid phases is given in table 2.

11 Table 2: Evaluation of the separation at $70{ }^{\circ} \mathrm{C}$ after 15 minutes calculated from the concentrations 12 obtained from Karl-Fischer titration $\left(\mathrm{H}_{2} \mathrm{O}\right)$, q ${ }^{1} \mathrm{H}$ NMR spectroscopy (NMPi and DES) and IR 13 spectroscopy (chemisorbed $\mathrm{CO}_{2}$ ). The percentages given correspond to the proportion of chemical present 14 in each phase considering a 70/30 volume ratio between organic and aqueous phases.

\begin{tabular}{lcc}
\hline & Organic phase & Aqueous phase \\
\hline Volumes & $70 \%$ & $30 \%$ \\
\hline $\mathrm{CO}_{2}$ & $60 \%$ & $36 \%$ \\
$\mathrm{H}_{2} \mathrm{O}$ & $62 \%$ & $38 \%$ \\
$\mathrm{NMPi}$ & $77 \%$ & $23 \%$ \\
$\mathrm{DES}$ & $99 \%$ & $1 \%$ \\
\hline
\end{tabular}

16 While the volume of the aqueous phase is $30 \%$, the amount of $\mathrm{CO}_{2}$ in this phase is $36 \%$ which 17 correspond to a moderate improvement of its concentration with the phase separation. This 18 modest separation is probably linked to the high concentration of water in the organic phase: $\mathrm{H}_{2} \mathrm{O}$ and $\mathrm{HCO}_{3}{ }^{-}$are similarly distributed between aqueous and organic phases. The majority of the $20 \mathrm{CO}_{2}$ has clearly not been concentrated in aqueous phase and the phase separation induced by 21 heating is inappropriate for a $\mathrm{CO}_{2}$ capture process in the conditions tested in this work. These 22 results could be compare to a well characterized biphasic system composed of water, $\mathrm{CO}_{2}$ and 23 three amines DMCA (N,N-dimethylcyclohexylamine), MCA (methylcyclohexylamine) and 24 MAPA (3-methylaminopropylamine) with around $30 \mathrm{wt} \%$ of amine at $60^{\circ} \mathrm{C}$, above the liquid - 
1 liquid separation.[40] In this case, concentrations of $\mathrm{CO}_{2}$ in both phases are around 1 and $5 \mathrm{wt} \%$ 2 in the organic and aqueous phase, respectively.[40] With such a large difference of concentration 3 between both phases, the organic phase could be send back directly to the sorption unit without 4 further treatment and the phase separation could be beneficial. In the case of DES (2:1), NMPi 5 and water $(15,15$, and $70 \mathrm{wt} \%)$, the difference of concentration of $\mathrm{CO}_{2}$ between both phases is 6 too small to apply this system in the field of carbon capture; 2.2 and $3.2 \mathrm{wt} \%$ of $\mathrm{CO}_{2}$ in organic 7 and aqueous phase, respectively. However, these primary results show the correct tendency. In 8 fact, it is remarkable to observe that both OA and LD are very well concentrated in the organic 9 phase while $\mathrm{CO}_{2}$ and water are poorly accumulated in the aqueous phase. 


\section{Conclusions}

2

3

4

5

6

A first example of an aqueous DES solution with a phase separation induced by the addition of $\mathrm{CO}_{2}$ at $20^{\circ} \mathrm{C}$ has been presented. In an aqueous solution of this DES based on OA and LD, bubbling $\mathrm{N}_{2}$ into the biphasic liquid - liquid system is switching back to a monophasic liquid. The quantity of $\mathrm{CO}_{2}$ absorbed into DES (OA:LD) - water mixture is moderate and this system could not be employ for the issue of carbon capture. However, aqueous solution of DES (OA:LD) could still be employed as a switchable hydrophobic solvent, where temperature or $\mathrm{CO}_{2}$ can be the stimulus inducing the switch.

Another amine (NMPi) was added into the solution to increase substantially the absorption of $\mathrm{CO}_{2}$. In the mixture with DES - NMPi - water $-\mathrm{CO}_{2}$, it is possible to tune the critical temperature with constant concentrations of water, DES, amine and $\mathrm{CO}_{2}$, simply by changing the (OA:LD) molar ratio of the DES. The temperature could be increase from around 30 to $70^{\circ} \mathrm{C}$ with higher concentrations of oleic acid. This possibility to adapt the critical temperature simply by changing the ratio of the two components of the DES is a practical way to adapt the property of the solvent to a specific application.

Unfortunately, the current system evaluated in this work does not have a good $\mathrm{CO}_{2}$ separation. Even if the DES is very well separated, the $\mathrm{CO}_{2}$ has been concentrated by only $20 \%$ in the aqueous phase compared to the homogenous solution. This system is a pioneer for upcoming research on $\mathrm{CO}_{2}$ capture by demixing solvent; it is illustrating the possibility to concentrate the $\mathrm{CO}_{2}$ in the aqueous phase using a DES composed of an amphiphilic (LD) and a hydrophobic (OA) molecules. Our forthcoming project will then focus on the screening of many parameters; concentrations of $\mathrm{OA}, \mathrm{LD}$, amine, water and $\mathrm{CO}_{2}$ as well as the possibility to test other DES and amine in order to found composition where the $\mathrm{CO}_{2}$ and water are less present in the organic phase. 


\section{$1 \quad$ Experimental details}

\section{Chemicals}

Lidocaine (LD, 99\% purity) and oleic acid (OA, 99\% purity) were obtained from TCI

4 chemical while N-methylpiperidine (NMPi, 99\% purity) was purchased from Sigma-Aldrich.

$5 \mathrm{CO}_{2}(99.995 \%)$ and $\mathrm{N}_{2}(99,2 \%)$ were supplied by Air Products. The water used was mono-

6 distilled and the methanol- $\mathrm{d}_{4}$ and $\mathrm{D}_{2} \mathrm{O}$ used for $\mathrm{q}{ }^{1} \mathrm{H}$ NMR (99\%) was purchased from Eurisotop.

\section{DES preparation}

8 DES (OA:LD) were prepared by heating the mixture at $80^{\circ} \mathrm{C}$ (above the melting temperature of the LD) for few minutes followed by a stirring to obtain a perfectly transparent liquid. DES and other liquid mixtures of $10 \mathrm{~g}$ were prepared with microbalance (precision of $+/-0.05 \mathrm{mg}$ ).

\section{Phase separation induced by $\mathrm{CO}_{2}$ sorption in aqueous solutions}

4 aqueous DES mixtures were prepared with $70 \mathrm{wt} \%$ of water. The compositions of DES were $45,50,55$ or $60 \mathrm{~mol} \%$ of OA. A magnetic stirrer and $2.5 \mathrm{~g}$ of the mixture were placed in a vial of $4 \mathrm{ml}$ (with a septum) and was equilibrated at $20^{\circ} \mathrm{C}$ in a thermostated bath (Julabo, ME-18V) for at least 15 minutes. A first picture of each vial was taken after stirring vigorously the monophasic liquid phase. Images were obtained using a camera (Logitec, C920). Some small bubbles could be observed at this stage because of the stirring. At this first stage, the gas phase in the vial was air at atmospheric pressure. Then, two needles have been used to flush gases into the vials. The first needle was used to add gas (either $\mathrm{N}_{2}$ or $\mathrm{CO}_{2}$ ) and was immerged into the liquid phase, while the other was used to release any overpressure. The gas was added using a balloon. During the second step, the $\mathrm{CO}_{2}$ was bubbled into the liquid under continuous stirring using a magnetic stirrer bar during 1 hour. Bubbles appearing out the first needle are used to confirm that the gas is

23 flushing slowly through the solution. The liquid was systematically becoming white during this step. The stirrer was then stopped and a second picture was taken after equilibration. Then, $\mathrm{N}_{2}$ has been flushed slowly during 1 hour under stirring of the solution and a third picture has been taken for each sample to illustrate the switch back to monophasic liquid. Identical results were obtained by two separated experiments. 
$\mathrm{CO}_{2}$ sorption was realized under continuous stirring at $40^{\circ} \mathrm{C}$ and under constant pressure of $0.2 \mathrm{MPa}$ of $\mathrm{CO}_{2}$ using a high pressure syringe pump (Teledyn Isco 260D). When the $\mathrm{CO}_{2}$ is in contact with the aqueous solution, the $\mathrm{CO}_{2}$ is absorbed and increase the weight of the solution. The $\mathrm{CO}_{2}$ sorption was then calculated with the mass uptake of the sample after sorption. $\mathrm{CO}_{2}$ was not bubbling directly into the liquid to prevent the loss of the solvent in the needle. The sorption 6 was then slow as taking place only at the gas - liquid interface. A typical $\mathrm{CO}_{2}$ sorption with $5 \mathrm{~g}$ of solution (water, DES and NMPi with 70, 15 and $15 \mathrm{wt} \%$, respectively) took about 40 minutes. After the vial was opened shortly to replace the $0.2 \mathrm{MPa}$ of $\mathrm{CO}_{2}$ of the gas phase by air at 9 atmospheric pressure. The typical uptake is around $160 \mathrm{mg}$ of $\mathrm{CO}_{2}$ with $\alpha=0.5$ for $5 \mathrm{~g}$ of solution. This experimental protocol was validated was the sorption of $\mathrm{CO}_{2}$ of well-known $\mathrm{MEA} / \mathrm{H}_{2} \mathrm{O}$ systems. The uncertainty of loading charges is estimated at $2 \%$.

\section{Visual determination of critical solution temperatures}

Critical solution temperatures were observed using a $2 \mathrm{ml}$ sample in a thermostated water bath equipped with two insulated glass windows (Julabo ME-18V). The bath was heated at a constant rate of $0.25^{\circ} \mathrm{C}$ per minute up to $80^{\circ} \mathrm{C}$ using the controller of the thermostated bath. Temperature of the water bath was measured with a $100 \Omega$ platinum resistance thermometer immerged in the water bath. During the heating, images were taken every two minutes by a camera (webcam, Logitec C920) and Yawcam software. The temperature was defined as the temperature of the first picture where the solution became cloudy. Uncertainty of critical temperatures is estimated at $+/$ $1{ }^{\circ} \mathrm{C}$.

\section{Quantification of chemicals in both phases}

NMR spectra were recorded in Fourier transform mode with a Bruker AVANCE 400 spectrometer at $298 \mathrm{~K}$. For the quantification, q ${ }^{1} \mathrm{H}$ NMR sequence (128 scans) according to references $[41,42]$ was used. Internal standard for $\mathrm{q}{ }^{1} \mathrm{H}$ NMR measurement of the organic phase (with DES) was 1,4-dimethoxybenzene (1,4-DMB, Aldrich), recrystallized twice in cyclohexane. Its purity (99.5\%) was determined using q ${ }^{1} \mathrm{H}$ NMR sequence with malonic acid (gold reference Aldrich). Methanol- $\mathrm{d}_{4}$ as solvent was used. Methoxy of the standard (s, $3.75 \mathrm{ppm}$ ), methyl of the NMPi (s, $2.50 \mathrm{ppm}$ ), aliphatic methyl of lidocaine and oleic acid, (t, $1.18 \mathrm{ppm}$ and t, $0.92 \mathrm{ppm}$ respectively) were used for the calculations. For the aqueous phase, 3-(trimethylsilyl)- 
1 propanesulfonic acid sodium salt (98\%, Aldrich) was used as standard in an 80/20 methanol-

$2 \mathrm{~d}_{4} / \mathrm{D}_{2} \mathrm{O}$ mixture as solvent. Trimethylsilyl ( $0.0 \mathrm{ppm}$, standard), methyl of NMPi (s, $2.63 \mathrm{ppm}$ ) and

3 methyl of lidocaine (1.15 ppm) were used.

4 The quantity of water in both phases was estimated with a Karl-Fischer Coulometer DL32 from 5 Mettler Toledo.

6 The relative concentration of $\mathrm{CO}_{2}$ before separation and in both phase after separation at $70^{\circ} \mathrm{C}$ 7 was obtained by ATR-FTIR spectroscopy. IR spectra were measured with a Nicolet 380 FT-IR 8 spectrometer equipped with a single reflection diamond ATR cell from Specac (Golden Gate) and 9 a DTGS detector. IR spectra were recorded at room temperature with a co-addition of 32 scans 10 and a resolution of $4 \mathrm{~cm}^{-1}$. Similar results $(+/-2 \%)$ were obtained from two separates samples for 11 all analyses (NMR, IR, KF). More technical details can be found elsewhere.[43-45]

\section{Acknowledgments}

14 The authors acknowledge the financial support received from the Agence Nationale de la 15 Recherche of the French government through the program "Investissements d'Avenir" (1616 IDEX-0001 CAP 20-25). Giovanni Ramdani and Juzaimi Nurhazwani are acknowledged for their 17 help during their graduations work in the preliminary screening of amines. 


\section{References}

2 [1] M. Bui, C.S. Adjiman, A. Bardow, E.J. Anthony, A. Boston, S. Brown, P.S. Fennell, S. Fuss, A. Galindo, L.A. Hackett, J.P. Hallett, H.J. Herzog, G. Jackson, J. Kemper, S. Krevor, G.C. Maitland, M. Matuszewski, I.S. Metcalfe, C. Petit, G. Puxty, J. Reimer, D.M. Reiner, E.S. Rubin, S.A. Scott, N. Shah, B. Smit, J.P.M. Trusler, P. Webley, J. Wilcox, N. Mac Dowell, Carbon capture and storage (CCS): the way forward, Energy Environ. Sci., 11 (2018) 1062-1176, doi:10.1039/C7EE02342A.

[2] A.B. Rao, E.S. Rubin, A Technical, Economic, and Environmental Assessment of Amine-Based CO2 Capture Technology for Power Plant Greenhouse Gas Control, Environ. Sci. Technol., 36 (2002) 44674475, doi:10.1021/es0158861.

[3] S. Zhang, Y. Shen, L. Wang, J. Chen, Y. Lu, Phase change solvents for post-combustion CO2 capture: Principle, advances, and challenges, Appl. Energy, 239 (2019) 876-897, doi:https://doi.org/10.1016/j.apenergy.2019.01.242.

[4] V. Feyzi, M. Beheshti, A. Gharibi Kharaji, Exergy analysis: A CO2 removal plant using a-MDEA as the solvent, Energy, 118 (2017) 77-84, doi:https://doi.org/10.1016/j.energy.2016.12.020.

[5] J. Zhang, R. Misch, Y. Tan, D.W. Agar, Novel Thermomorphic Biphasic Amine Solvents for CO2 Absorption and Low-Temperature Extractive Regeneration, Chem. Eng. Technol., 34 (2011) 1481-1489, doi:https://doi.org/10.1002/ceat.201100099.

[6] L. Raynal, P. Alix, P.-A. Bouillon, A. Gomez, M.I.F. de Nailly, M. Jacquin, J. Kittel, A. di Lella, P. Mougin, J. Trapy, The DMX'M process: An original solution for lowering the cost of post-combustion carbon capture, Energy Procedia, 4 (2011) 779-786, doi:https://doi.org/10.1016/j.egypro.2011.01.119. [7] L. Raynal, P. Briot, M. Dreillard, P. Broutin, A. Mangiaracina, B.S. Drioli, M. Politi, C. La Marca, J. Mertens, M.-L. Thielens, G. Laborie, L. Normand, Evaluation of the DMX Process for Industrial Pilot Demonstration - Methodology and Results, Energy Procedia, 63 (2014) 6298-6309, doi:https://doi.org/10.1016/j.egypro.2014.11.662.

[8] J. Zhang, D.W. Agar, X. Zhang, F. Geuzebroek, CO2 absorption in biphasic solvents with enhanced low temperature solvent regeneration, Energy Procedia, 4 (2011) 67-74, doi:https://doi.org/10.1016/j.egypro.2011.01.024.

[9] J. Zhang, O. Nwani, Y. Tan, D.W. Agar, Carbon dioxide absorption into biphasic amine solvent with solvent loss reduction, Chem. Eng. Res. Des., 89 (2011) 1190-1196, doi:https://doi.org/10.1016/j.cherd.2011.02.005.

[10] J. Zhang, Y. Qiao, D.W. Agar, Improvement of Lipophilic-Amine-based Thermomorphic Biphasic Solvent for Energy-Efficient Carbon Capture, Energy Procedia, 23 (2012) 92-101, doi:https://doi.org/10.1016/j.egypro.2012.06.072. [11] J. Zhang, Y. Qiao, D.W. Agar, Intensification of low temperature thermomorphic biphasic amine solvent regeneration for $\mathrm{CO} 2$ capture, Chem. Eng. Res. Des., 90 (2012) 743-749, doi:https://doi.org/10.1016/j.cherd.2012.03.016.

[12] J. Zhang, Y. Qiao, W. Wang, R. Misch, K. Hussain, D.W. Agar, Development of an Energy-efficient CO2 Capture Process Using Thermomorphic Biphasic Solvents, Energy Procedia, 37 (2013) 1254-1261, doi:https://doi.org/10.1016/j.egypro.2013.05.224.

[13] Y. Zhang, C.-C. Chen, Thermodynamic Modeling for CO2 Absorption in Aqueous MDEA Solution with Electrolyte NRTL Model, Ind. Eng. Chem. Res., 50 (2011) 163-175, doi:10.1021/ie1006855.

[14] Y. Zhang, H. Que, C.-C. Chen, Thermodynamic modeling for $\mathrm{CO} 2$ absorption in aqueous MEA solution with electrolyte NRTL model, Fluid Phase Equilib., 311 (2011) 67-75, doi:https://doi.org/10.1016/j.fluid.2011.08.025.

[15] Y.H. Tan, Study of CO2 absorption into thermomorphic lipophilic amine solvents, in, 2010. [16] M.W. Arshad, H.F. Svendsen, P.L. Fosbøl, N. von Solms, K. Thomsen, Equilibrium Total Pressure and CO2 Solubility in Binary and Ternary Aqueous Solutions of 2-(Diethylamino)ethanol (DEEA) and 3(Methylamino)propylamine (MAPA), J. Chem. Eng. Data, 59 (2014) 764-774, doi:10.1021/je400886w. 
[17] A.F. Ciftja, A. Hartono, H.F. Svendsen, Experimental study on phase change solvents in $\mathrm{CO} 2$ capture by NMR spectroscopy, Chem. Eng. Sci., 102 (2013) 378-386, doi:https://doi.org/10.1016/i.ces.2013.08.036.

[18] J.G.M.S. Monteiro, H. Majeed, H. Knuutila, H.F. Svendsen, Kinetics of $\mathrm{CO} 2$ absorption in aqueous blends of N,N-diethylethanolamine (DEEA) and N-methyl-1,3-propane-diamine (MAPA), Chem. Eng. Sci., 129 (2015) 145-155, doi:https://doi.org/10.1016/i.ces.2015.02.001.

[19] J.G.M.S. Monteiro, D.D.D. Pinto, S.A.H. Zaidy, A. Hartono, H.F. Svendsen, VLE data and modelling of aqueous N,N-diethylethanolamine (DEEA) solutions, Int. J. Greenh. Gas Control, 19 (2013) 432-440, doi:https://doi.org/10.1016/i.ijggc.2013.10.001.

[20] D.D.D. Pinto, H. Knuutila, G. Fytianos, G. Haugen, T. Mejdell, H.F. Svendsen, CO2 post combustion capture with a phase change solvent. Pilot plant campaign, Int. J. Greenh. Gas Control, 31 (2014) 153164, doi:https://doi.org/10.1016/j.ijggc.2014.10.007.

[21] Z. Xu, S. Wang, J. Liu, C. Chen, Solvents with Low Critical Solution Temperature for CO2 Capture, Energy Procedia, 23 (2012) 64-71, doi:https://doi.org/10.1016/i.egypro.2012.06.045.

[22] Q. Ye, X. Wang, Y. Lu, Screening and evaluation of novel biphasic solvents for energy-efficient postcombustion CO2 capture, Int. J. Greenh. Gas Control, 39 (2015) 205-214, doi:https://doi.org/10.1016/i.ijggc.2015.05.025.

[23] A.P. Abbott, G. Capper, D.L. Davies, R.K. Rasheed, V. Tambyrajah, Novel solvent properties of choline chloride/urea mixtures, Chem. Commun., (2003) 70-71.

[24] A.P. Abbott, D. Boothby, G. Capper, D.L. Davies, R.K. Rasheed, Deep Eutectic Solvents Formed between Choline Chloride and Carboxylic Acids: Versatile Alternatives to lonic Liquids, J. Am. Chem. Soc., 126 (2004) 9142-9147, doi:10.1021/ja048266j.

[25] Q. Zhang, K. De Oliveira Vigier, S. Royer, F. Jérôme, Deep eutectic solvents: syntheses, properties and applications, Chem. Soc. Rev., 41 (2012) 7108-7146, doi:10.1039/C2CS35178A.

[26] D.J.G.P. van Osch, L.F. Zubeir, A. van den Bruinhorst, M.A.A. Rocha, M.C. Kroon, Hydrophobic deep eutectic solvents as water-immiscible extractants, Green Chem., 17 (2015) 4518-4521, doi:10.1039/C5GC01451D.

[27] D.J.G.P. van Osch, D. Parmentier, C.H.J.T. Dietz, A. van den Bruinhorst, R. Tuinier, M.C. Kroon, Removal of alkali and transition metal ions from water with hydrophobic deep eutectic solvents, Chem. Commun., 52 (2016) 11987-11990, doi:10.1039/C6CC06105B.

[28] O. Longeras, A. Gautier, K. Ballerat-Busserolles, J.-M. Andanson, Deep Eutectic Solvent with ThermoSwitchable Hydrophobicity, ACS Sustain Chem Eng, 8 (2020) 12516-12520, doi:10.1021/acssuschemeng.0c03478.

[29] K. Bica, J. Shamshina, W.L. Hough, D.R. MacFarlane, R.D. Rogers, Liquid forms of pharmaceutical cocrystals: exploring the boundaries of salt formation, Chem. Commun., 47 (2011) 2267-2269, doi:10.1039/COCC04485G.

[30] R.C. Weast, M.J. Astle, CRC Handbook of Chemistry and Physics...: 1983-1984, CRC press, 1983. [31] J. Cassens, A. Prudic, F. Ruether, G. Sadowski, Solubility of Pharmaceuticals and Their Salts As a Function of pH, Ind. Eng. Chem. Res., 52 (2013) 2721-2731, doi:10.1021/ie302064h.

[32] I.M. Bernhardsen, H.K. Knuutila, A review of potential amine solvents for $\mathrm{CO} 2$ absorption process: Absorption capacity, cyclic capacity and pKa, Int. J. Greenh. Gas Control, 61 (2017) 27-48, doi:https://doi.org/10.1016/j.ijggc.2017.03.021.

[33] Y. Kohno, H. Arai, H. Ohno, Dual stimuli-responsive phase transition of an ionic liquid/water mixture, Chem. Commun., 47 (2011) 4772-4774, doi:10.1039/C1CC10613A.

[34] G. Puxty, R. Rowland, A. Allport, Q. Yang, M. Bown, R. Burns, M. Maeder, M. Attalla, Carbon Dioxide Postcombustion Capture: A Novel Screening Study of the Carbon Dioxide Absorption Performance of 76 Amines, Environ. Sci. Technol., 43 (2009) 6427-6433, doi:10.1021/es901376a. 
[35] I. Adeyemi, M.R.M. Abu-Zahra, I. Alnashef, Novel Green Solvents for CO2 Capture, Energy Procedia, 114 (2017) 2552-2560, doi:https://doi.org/10.1016/j.egypro.2017.03.1413.

3 [36] H. Sakurai, J. Pokorný, The development and application of novel vegetable oils tailor-made for 4 specific human dietary needs, Eur. J. Lipid Sci. Technol., 105 (2003) 769-778,

5 doi:https://doi.org/10.1002/ejlt.200300890. [37] Q. Chen, L. Wang, G. Ren, Q. Liu, Z. Xu, D. Sun, A fatty acid solvent of switchable miscibility, J. Colloid Interface Sci., 504 (2017) 645-651, doi:https://doi.org/10.1016/j.jcis.2017.06.011.

[38] Y. Coulier, A.R. Lowe, A. Moreau, K. Ballerat-Busserolles, J.Y. Coxam, Liquid-liquid phase separation of \{amine - H2O - CO2\} systems: New methods for key data, Fluid Phase Equilibria, 431 (2017) 1-1-7, doi:10.1016/j.fluid.2016.10.010.

[39] G. Richner, G. Puxty, Assessing the Chemical Speciation during CO2 Absorption by Aqueous Amines Using in Situ FTIR, Ind. Eng. Chem. Res., 51 (2012) 14317-14324, doi:10.1021/ie302056f.

[40] F. Tzirakis, I. Tsivintzelis, A.I. Papadopoulos, P. Seferlis, Experimental measurement and assessment of equilibrium behaviour for phase change solvents used in CO2 capture, Chem. Eng. Sci., 199 (2019) 2027, doi:https://doi.org/10.1016/j.ces.2018.12.045.

[41] G.F. Pauli, S.-N. Chen, C. Simmler, D.C. Lankin, T. Gödecke, B.U. Jaki, J.B. Friesen, J.B. McAlpine, J.G. Napolitano, Importance of Purity Evaluation and the Potential of Quantitative $1 \mathrm{H}$ NMR as a Purity Assay, J. Med. Chem., 57 (2014) 9220-9231, doi:10.1021/jm500734a.

[42] J.I. Lee, F.D. Otto, A.E. Mather, Equilibrium between carbon dioxide and aqueous monoethanolamine solutions, J. Appl. Chem. Biotechnol., 26 (1976) 541-549, doi:10.1002/jctb.5020260177.

[43] O. Longeras, PhD., Design and Comprehension of New Deep Eutectic Solvents, in, Université Clermont Auvergne, 2020.

[44] E. Brugère, J.-M. Andanson, K. Ballerat-Busserolles, The Use of IR Spectroscopy to Follow the Absorption of $\mathrm{CO} 2$ in Amine Media - Evaluation of the Speciation with Time, in: Gas Injection into Geological Formations and Related Topics, 2020, pp. 41-53.

[45] Y. Coulier, W. Ravisy, J.-M. Andanson, J.-Y. Coxam, K. Ballerat-Busserolles, Experiments and Modeling for $\mathrm{CO} 2$ Capture Processes Understanding, in: Cutting-Edge Technology for Carbon Capture, Utilization, and Storage, 2018, pp. 235-254. 